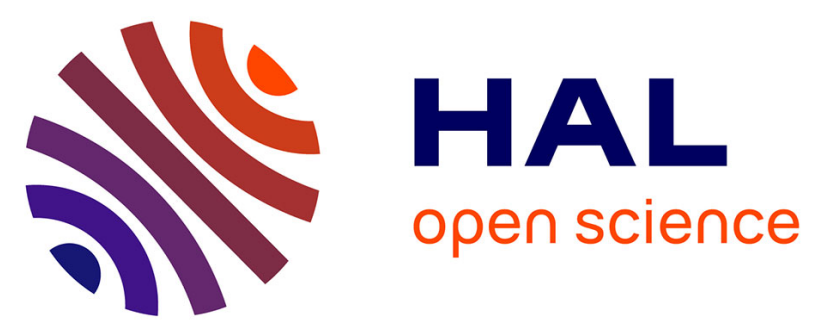

\title{
All-Silica SSZ-74 Synthesized in Fluoride or Fluoride-Free Media: Investigation on the Organic Structure-Directing Agent's Locations Inside Pores
}

Carole Isaac, Irena Deroche, Jean-Louis Paillaud, T. Jean Daou, Andrey Ryzhikov, Laure Michelin, Séverinne Rigolet, Ludovic Josien, Habiba Nouali

\section{To cite this version:}

Carole Isaac, Irena Deroche, Jean-Louis Paillaud, T. Jean Daou, Andrey Ryzhikov, et al.. All-Silica SSZ-74 Synthesized in Fluoride or Fluoride-Free Media: Investigation on the Organic StructureDirecting Agent's Locations Inside Pores. Crystal Growth \& Design, 2021, 21 (7), pp.4013-4022. 10.1021/acs.cgd.1c00322 . hal-03410510

\author{
HAL Id: hal-03410510 \\ https://hal.science/hal-03410510
}

Submitted on 1 Nov 2021

HAL is a multi-disciplinary open access archive for the deposit and dissemination of scientific research documents, whether they are published or not. The documents may come from teaching and research institutions in France or abroad, or from public or private research centers.
L'archive ouverte pluridisciplinaire HAL, est destinée au dépôt et à la diffusion de documents scientifiques de niveau recherche, publiés ou non, émanant des établissements d'enseignement et de recherche français ou étrangers, des laboratoires publics ou privés. 


\title{
All-Silica SSZ-74 Synthesized in Fluoride or Fluoride-Free Media: Investigation on the OSDA's Location Inside the Porosity
}

\author{
Carole Isaac, ${ }^{\dagger, \ddagger}$ Irena Deroche, ${ }^{\dagger, \ddagger}$ Jean-Louis Paillaud, ${ }^{*, \dagger, \ddagger}$ T. Jean Daou, ${ }^{\dagger, \ddagger}$ Andrey \\ Ryzhikov, ${ }^{\dagger, \ddagger}$ Laure Michelin, ${ }^{\dagger, \ddagger}$ Séverinne Rigolet, ${ }^{\dagger, \ddagger}$ Ludovic Josien, ${ }^{\dagger, \ddagger}$ and Habiba \\ Nouali \\ †Université de Haute Alsace (UHA), CNRS, IS2M UMR 7361, F-68100 Mulhouse, France \\ $\ddagger$ Université de Strasbourg, F-67000 Strasbourg, France \\ E-mail: jean-louis.paillaud@uha.fr
}

\begin{abstract}
Pure silica SSZ-74 zeolite (-SVR type) was synthesized in fluoride or fluoride-free media using the hydroxide salts of the symmetric 1,6-bis(N-methylpyrrolidinium)hexane and asymmetric 1-methyl-1-[6-(trimethyl-azaniumyl)-hexyl]pyrrolidinium diquats as organic structure-directing agents (OSDA). A structural study using the Rietveld method revealed unexpected orientation of the OSDAs inside the micropores of the zeolite. Unlike the original structural elucidation, which proposed the OSDA's location inside the channel parallel to $c$-axis in a distorted conformation, in both samples, the OSDAs are here located elsewhere, inside the undulated connecting-channels along the [110] direction and in a more favorable linear conformation. This surprising result was confirmed on an energy point of view by computational method together with solid-state NMR experiments. Moreover, the impact of a thermal treatment on this particular structure
\end{abstract}


containing ordered vacancies was studied by high-temperature powder X-ray diffraction under different atmospheres.

\section{Keywords}

Zeolite synthesis; organic structure-directing agent (OSDA); SSZ-74 (-SVR); Rietveld refinement; force field geometry optimization; ${ }^{13} \mathrm{C},{ }^{29} \mathrm{Si}$ and ${ }^{19} \mathrm{~F}$ solid-state NMR 


\section{Introduction}

Hydrophobic high-silica zeolites are of particular interest for the storage or adsorption of mechanical energy. They can accumulate, restore or dissipate mechanical energy using water or aqueous solutions of electrolytes, which are non-wetting liquid for zeosils. 14 Adsorption properties of these zeolites are also very attractive, because they can clean up the air by adsorbing volatile organic compounds, without being affected by humidity present. $\stackrel{516}{\text { Pure- }}$ silica zeolite can be used as less dense insulator, for example in integrated circuits. ${ }^{[7}$ That is why increasing the silica content has been a challenge for the past decades. The synthesis of pure and high silica zeolites has been very fruitful thanks to organocations, especially diquaternary ammonium salts. $\stackrel{8-10}{-10}$ Among them, diquaternary alkylammonium ions having a N-heterocycle have directed the crystallization of many zeolites in hydroxide or fluoride medium. $11+15$ Indeed, the addition of fluoride ions in the synthesis gel increases the solubility of the inorganic species, it is especially suited for pure-silica syntheses which can be prepared with a better yield of crystallization in a more neutral media with less connectivity defects. $\underline{16}[18$ This fluoride route enabled the formation of open frameworks which are favored in concentrated media. The fluoride anions have a structure directing-effect helping the crystallization of new topologies because of their stabilization role of $d_{4} r$ units. $\frac{1921}{21}$ However, the substantial toxicity of hydrofluoric acid is a challenge for large scale syntheses of these zeolites.

A high-silica zeolite SSZ-74 (-SVR-topology) was first obtained using 1,6-bis(N-methylpyrrolidinium)hexane (Figure 1a) as OSDA by Zones et al. in fluoride medium and also in hydroxide medium. ${ }^{22 \mid 23}$ The structure of SSZ-74 was published in 2008 by Baerlocher et al., 24 it was solved from high-resolution transmission electron microscopy, synchrotron powder data and molecular modeling was used to locate the OSDA inside the pores. Later, atomistic simulation confirmed the structure. ${ }^{25}$ The asymmetric unit of SSZ-74 contains 23 T atoms forming an uncommon framework with ordered silicon vacancies, the 3D-channels system contains 10 -membered ring pore openings. In the original publication, 24 there is no 
mention of the presence or not of fluoride inside the zeolite but in 2016, Zones et al. published a study on the $\mathrm{SiOH}$ and $\mathrm{SiO}^{-}$defects of some zeolites with different topologies including -SVR using, among other techniques of characterization, ${ }^{19} \mathrm{~F}$ solid-state NMR. ${ }^{26}$ It was mentioned that there must be about two fluoride anions per unit cell and that some of them are forming pentacoordinated silicon and the other are in not well-defined single position. According to this description, the OSDA molecules are oriented along the channels parallel to the $c$-axis, with the two methylpyrrolidine heads positioned in the cavities formed by the ordered silicon vacancies as illustrated in Figure 2. The structural relationship between the shape of the OSDA (including 1,6-bis(N-methylpyrrolidinium)hexane) and zeolite framework has been an illustration of structure-directing phenomenon mentioned in several works that combined X-rays experiments and molecular simulation. $10[27,30$

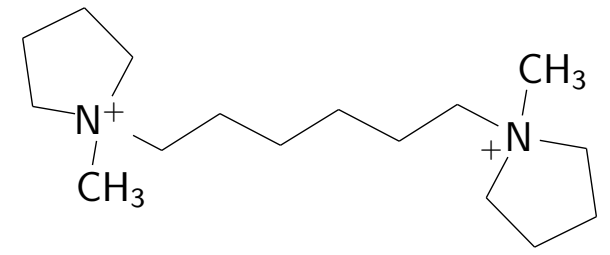

(a) $\left(\mathrm{C}_{4} \mathrm{~N}\right)\left[\mathrm{C}_{6}\right]\left(\mathrm{NC}_{4}\right)$

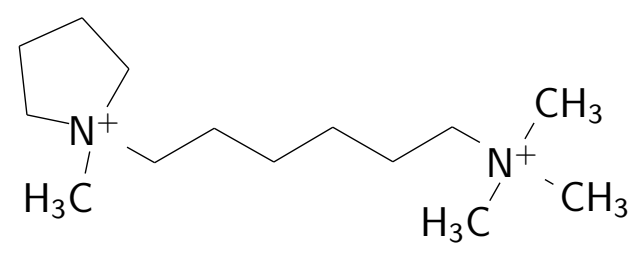

(b) $\mathrm{TM}\left[\mathrm{C}_{6}\right]\left(\mathrm{NC}_{4}\right)$

Figure 1: OSDAs used for the synthesis of SSZ-74: (a) 1,6-bis(N-methylpyrrolidinium)hexane and (b) 1-methyl-1-[6-(trimethylazaniumyl)hexyl]pyrrolidinium.

In this contribution, a new fluoride-free synthesis of pure silica SSZ-74 is reported using an uncommon asymmetric OSDA molecule: 1-methyl-1-[6-(trimethylazaniumyl)hexyl]pyrrolidinium dihydroxide $\left(\mathrm{TM}_{6}\left[\mathrm{C}_{6}\right]\left(\mathrm{NC}_{4}\right)\right.$ in Figure $\left.1 \mathrm{~b}\right)$. Its structural study as well as the one performed on the same zeolite synthesized in fluoride medium with the original symmetric OSDA $\left(\left(\mathrm{C}_{4} \mathrm{~N}\right)\left[\mathrm{C}_{6}\right]\left(\mathrm{NC}_{4}\right)\right.$ in Figure $\left.1 \mathrm{a}\right)$ by the Rietveld method ${ }^{[31}$ has revealed a different location of the OSDAs. Computational method confirmed the results from an energy point of view, as well as multi-nuclei solid state NMR experiments. Thermal treatments on this particular structure were also performed under different atmospheres in order to verify its stability. 

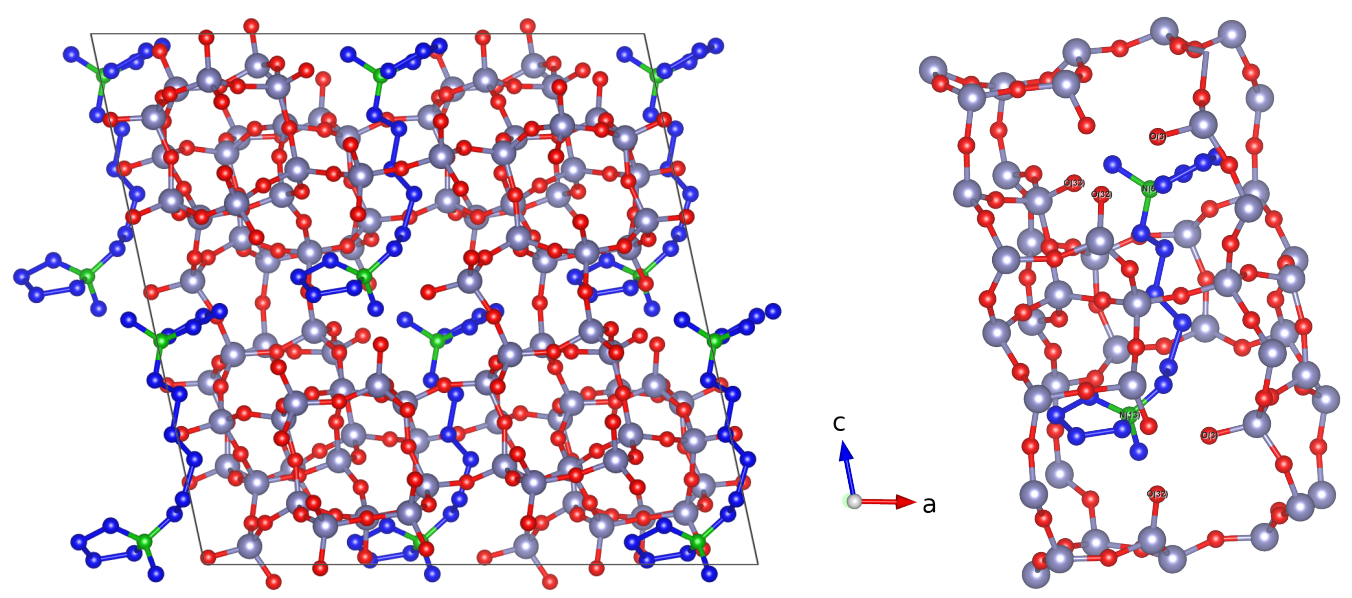

Figure 2: Projection along [010] of SSZ-74 and details showing the interactions between the OSDA $\left(\left(\mathrm{C}_{4} \mathrm{~N}\right)\left[\mathrm{C}_{6}\right]\left(\mathrm{NC}_{4}\right)\right)$ and the framework according to Baerlocher et al. ${ }^{24}$ The atoms are colored in grey for silicon, red for oxygen, blue for carbon and green for nitrogen.

\section{Experimental}

\section{Synthesis}

Synthesis of the OSDAs. The asymmetric organic molecule, 1-methyl-1-[6-(trimethylazaniumyl)hexyl|pyrrolidinium, was purchased under its iodine form (OTAVA Chemicals). The symmetric usual OSDA for SSZ-74 synthesis, 1,6-bis(N-methylpyrrolidinium)-hexane was prepared in acetone (Carlo Erba) for three days, at room temperature, with an excess of N-methylpyrrolidine (Fluka) and 1,6-dibromohexane (Sigma Aldrich) following the protocol described by Zones et al. ${ }^{[22}$ Both OSDAs were exchanged several times to obtain their hydroxide form. Each exchange was done overnight, with $50 \%$ excess in Dowex $^{\mathrm{TM}}$ Monosphere $^{\mathrm{TM}}$ 550 A UPW (OH) (Supelco) resin. In each case, a final conversion rate of about $99 \%$ was determined by titration with a hydrochloric acid solution of concentration $10^{-2} \mathrm{~mol} \mathrm{~L}^{-1}$. The concentrations of the OSDA's aqueous solutions were determined thanks to ${ }^{1} \mathrm{H}$ liquid NMR using a $0.5 \mathrm{~mol} \mathrm{~L}^{-1}$ solution of dioxane in deuterium oxide as internal standard.

Zeolite synthesis. Tetraethoxysilane was used as silica source (TEOS, Aldrich, 98\%). The mineralizing species were fluoride ions from hydrofluoric acid (Normapur, 40\%) or 
hydroxide counter ions of the OSDAs. For the hydrothermal syntheses, the reactants are directly introduced in the Teflon ${ }^{\circledR}$ liners. The TEOS and the OSDA's solutions were mixed under stirring. Then, the ethanol formed by the hydrolysis of TEOS and the potential excess of water were evaporate at room temperature for a minimum of one day. Water and hydrofluoric acid were added to the gel to reach the desired ratios (Table 1). The liners containing the reaction mixture were introduced into a stainless-steel multiautoclave. The hydrothermal treatments were carried out at the temperatures and durations listed in Table 1. The solids were recovered by filtration, washed several times with demineralized water and ethanol and finally dried overnight at $60{ }^{\circ} \mathrm{C}$.

Table 1: Experimental molar compositions of the starting synthesis gels and their synthesis conditions.

\begin{tabular}{cccccccc}
\hline \multirow{2}{*}{ Sample } & \multirow{2}{*}{$\mathrm{R}(\mathrm{OH})_{2}$} & \multicolumn{3}{c}{ Molar proportions } & \multicolumn{2}{c}{$\begin{array}{c}\text { Duration } \\
(\text { Temperature }\end{array}$} \\
& & $\mathrm{SiO}_{2}$ & $\mathrm{R}(\mathrm{OH})_{2}$ & $\mathrm{HF}$ & $\mathrm{H}_{2} \mathrm{O}$ & $($ Days $)$ & $\left({ }^{\circ} \mathrm{C}\right)$ \\
\hline Ref & $\left(\mathrm{C}_{4} \mathrm{~N}\right)\left[\mathrm{C}_{6}\right]\left(\mathrm{NC}_{4}\right)$ & 0.80 & 0.40 & 0.26 & 2.8 & 22 & 150 \\
Asym160 & $\left.\mathrm{TM}_{6}\right]\left(\mathrm{NC}_{4}\right)$ & 0.80 & 0.40 & 0 & 30 & 22 & 160 \\
Sym160 & $\left(\mathrm{C}_{4} \mathrm{~N}\right)\left[\mathrm{C}_{6}\right]\left(\mathrm{NC}_{4}\right)$ & 0.80 & 0.40 & 0 & 30 & 22 & 160 \\
Asym170 & $\mathrm{TM}\left[\mathrm{C}_{6}\right]\left(\mathrm{NC}_{4}\right)$ & 0.80 & 0.40 & 0 & 30 & 15 & 170 \\
Sym170 & $\left(\mathrm{C}_{4} \mathrm{~N}\right)\left[\mathrm{C}_{6}\right]\left(\mathrm{NC}_{4}\right)$ & 0.80 & 0.40 & 0 & 30 & 15 & 170 \\
\hline
\end{tabular}

The first fluorine-free synthesis of SSZ-74 found was Asym170. After that, different syntheses were made to optimize it. A reference sample (Ref) was prepared following the usual protocol described by Zones et al. $\stackrel{22}{ }$ Sym170 was synthesized with the original symmetric template in the new conditions. Both OSDA were also tested in fluoride-free hydrothermal synthesis carried out at $160{ }^{\circ} \mathrm{C}(\mathbf{S y m} 160$ and Asym160) which is between the temperature of the new (Asym170) and the original synthesis (Ref). 


\section{Characterizations}

PXRD. The PXRD patterns were recorded on a STOE STADI-P diffractometer equipped with a linear position-sensitive detector and a curved germanium (111) primary monochromator ( $\mathrm{CuK} \alpha_{1}$ radiation). For Sym170, Sym160 and Asym160 samples, $2 \theta$ angle values were between $5-50^{\circ}$ range $\left(\mathrm{PSD}\right.$ step $=0.28^{\circ}$, time $/$ step $\left.=15 \mathrm{~s}\right)$. For the structural analysis from Rietveld refinement (Ref and Asym170 samples), two scans were collected at room temperature $(293 \mathrm{~K})$ for $2 \theta$ angle values in the $5-90^{\circ}$ range $\left(\mathrm{PSD}\right.$ step $=0.1^{\circ}$, time $/$ step $=$ $117 \mathrm{~s})$. Both scans were averaged to statistically improve the collected data.

Table 2: Recording conditions of the MAS NMR spectra.

\begin{tabular}{lcccc}
\hline & ${ }^{29} \mathrm{Si} \mathrm{MAS}+\mathrm{DEC}$ & ${ }^{1} \mathrm{H}-{ }^{29} \mathrm{Si}$ CPMAS & ${ }^{19} \mathrm{~F}$ MAS & ${ }^{1} \mathrm{H}-{ }^{13} \mathrm{C}$ CPMAS \\
\hline Chemical shift standard & TMS & TMS & $\mathrm{CFCl}_{3}$ & $\mathrm{TMS}$ \\
Probe (mm) & 7 & 7 & 2.5 & 4 \\
Frequency (MHz) & 59.62 & 59.62 & 376.47 & 100.62 \\
Pulse width (us) & 1.83 & 5.5 & 2.5 & 5.6 \\
Contact time (ms) & - & 4 & 4 & 1 \\
Flip angle & $\pi / 6$ & $\pi / 2$ & $\pi / 2$ & $\pi / 2$ \\
Recycle time (s) & 80 & 5 & 40 & 5 \\
Spinning rate (kHz) & 4 & 4 & 25 & 12 \\
Number of scans & $3153 ; 5052^{\mathrm{a}}$ & $1785 ; 3549^{\mathrm{a}}$ & 2030 & 3274 \\
\hline
\end{tabular}

${ }^{a}$ Number of scans for, respectively, Ref and Asym170 samples.

Solid-state and liquid NMR spectroscopy. ${ }^{29} \mathrm{Si} \mathrm{MAS}+\mathrm{DEC}$ and ${ }^{1} \mathrm{H}^{-29} \mathrm{Si}$ cross polarisation MAS (CPMAS) experiments were performed with a Bruker Avance NEO $300 \mathrm{MHz}$ spectrometer equipped with a Bruker $7 \mathrm{~mm}$ probe. The quantitative determination of the proportions of the different $\mathrm{Q}^{n} \mathrm{Si}$ species was ensured by the recording conditions. ${ }^{32}$ The spectra were analysed using the Dmfit software. ${ }^{33}{ }^{13} \mathrm{C}$ CPMAS and ${ }^{19} \mathrm{~F}$ MAS NMR experiments were performed on a Bruker Avance NEO $400 \mathrm{MHz}$ spectrometer equipped with Bruker $4 \mathrm{~mm}$ and $2.5 \mathrm{~mm}$ probes, respectively. The recording conditions are given in Table 2. All spectra were recorded at room temperature. The liquid NMR spectra of the OSDA were recorded on a Bruker Avance Neo 500 spectrometer in deuterium oxide. Liquid ${ }^{13} \mathrm{C}$ 
NMR spectra were recorded after dissolving about $50 \mathrm{mg}$ of zeolite in $300 \mu \mathrm{L}$ of $\mathrm{HF} 40 \mathrm{wt} \%$ at a frequency of $125.7 \mathrm{MHz}$ with 1682 scans (acquisition time of $1.0879 \mathrm{~s}$ ).

SEM. The morphology and size of the crystals were determined by scanning electron microscopy (SEM) thanks to a high-resolution scanning electron microscope (Jeol, JSM-7900F). Samples were observed without coating at a low accelerating voltage of $2 \mathrm{kV}$.

High-temperature PXRD. To understand how zeolites of topology -SVR behave under heating treatment, a series of PXRD patterns were recorded on a thermodiffractometer (PANalytical, X'Pert PRO MPD) equipped with an Anton Paar HTK1200 temperature chamber. The experiments were conducted under dry helium and air flow, with a gradual temperature rise of $1^{\circ} \mathrm{C} / \mathrm{min}$, a diffraction pattern was collected every $50{ }^{\circ} \mathrm{C}\left(5-60^{\circ}(2 \theta)\right.$, PSD step $=0.05^{\circ}$, time $/$ step $\left.=1.63 \mathrm{~s}\right)$ until $950{ }^{\circ} \mathrm{C}($ Figure $\mathrm{S} 5)$.

Textural properties. Nitrogen adsorption-desorption isotherms were performed using a Micromeritics ASAP 2420 apparatus. Therefore, a calcination of SSZ-74 Ref sample was done with a temperature rise of $1^{\circ} \mathrm{C} / \mathrm{min}$, a first step at $300^{\circ} \mathrm{C}$ for 5 hours, then $550{ }^{\circ} \mathrm{C}$ for 10 hours. Before the adsorption measurements, the sample was out-gassed under vacuum at $90^{\circ} \mathrm{C}$ then $300^{\circ} \mathrm{C}$ during 1 hour and 15 hours to eliminate physisorbed water. The specific surface area $\left(\mathrm{S}_{\mathrm{BET}}\right)$ and microporous volume $\left(\mathrm{V}_{\text {micro }}\right)$ were calculated using the BET and t-plot methods, respectively. $\stackrel{34 \mid 35}{ }$ Additionally, thermogravimetric analyses were performed on a METTLER Toledo thermogravimetric analyzer between $30^{\circ} \mathrm{C}$ and $800^{\circ} \mathrm{C}$, the temperature increasing at a constant rate of $5{ }^{\circ} \mathrm{C} / \min$ up to $800^{\circ} \mathrm{C}$.

Rietveld Refinement. The PXRD patterns of samples Ref and Asym170 were first indexed in a monoclinic $C$-centered unit cell with the parameters $a=20.461(4) \AA, b=$ 13.390(3) $\AA, c=20.142(4) \AA, \beta=102.346(12)^{\circ}, \quad V=5390.7(20) \AA^{3}$ and $a=20.405(4) \AA$, 
$b=13.386(3) \AA, c=20.146(4) \AA, \beta=102.723(13)^{\circ}, V=5367.6(27) \AA^{3}$, respectively, by the Louër's indexing DICVOL91 $1^{36}$ module of the STOE WinX ${ }^{P O W}$ suite of programs. $\frac{37}{37}$ The observed systematic extinctions did not suggest a different space group other than $C c$ attributed to SSZ-74.24 The Rietveld analyses were conducted with the free software suite GSAS-II ${ }^{38}$ In a first step, a Le Bail refinement ${ }^{39}$ allowed us to determine the background and profile parameters and to refine the unit cell parameters. Then, the atomic coordinates of the whole framework atoms of SSZ-74 ${ }^{24}$ (i.e. $\mathrm{T}$ and $\mathrm{O}$ atoms) were used as the starting model for the Rietveld refinement. Soft restraints were placed on the bond lengths and angles of the framework $\left(\mathrm{T}-\mathrm{O}=1.62(4) \AA\right.$ and $\left.\mathrm{O}-\mathrm{T}-\mathrm{O}=109.5(30)^{\circ}\right)$. In a first stage and in order to determine a proper scale factor, only the high angle window $\left(50<2 \theta<90^{\circ}\right)$ was take into account, $\stackrel{40}{a}$ then the whole pattern was used for the following steps. All the atoms were refined isotropically. After refinement of the framework, the calculated Fourier difference maps revealed, for Ref and Asym170, scattering densities inside the void volume unambiguously attributable to the OSDAs (Figure 3). They clearly indicate that the OSDAs are lodged in channels parallel to the $a$ axis, more precisely along a direction close to [110].

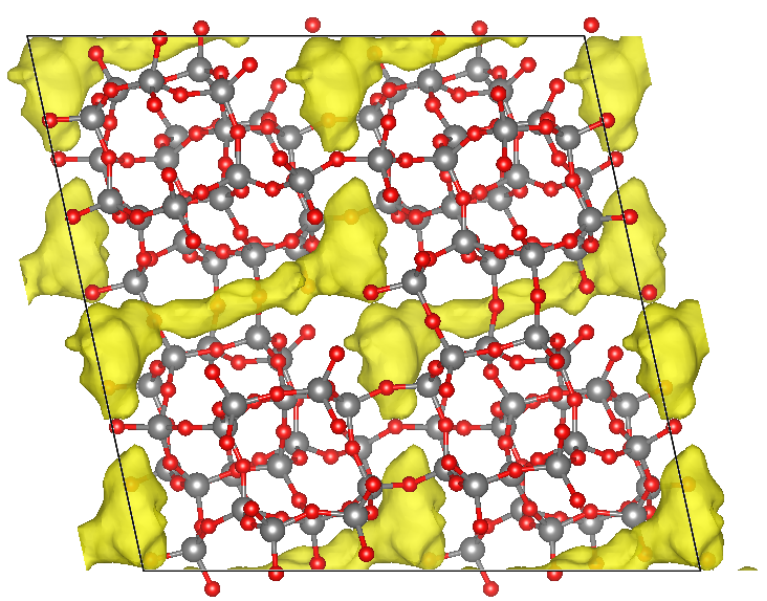

(a)

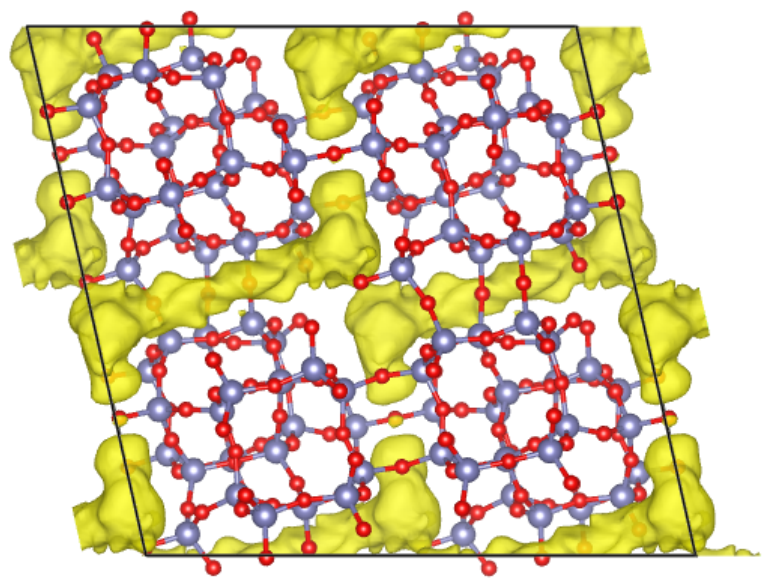

(b)

Figure 3: Projection along [010] of SSZ-74 showing the residual electron density maps obtained by Fourier difference after the first step of the Rietveld refinement, located in the undulating channels along the [110] direction for samples (a) Ref and (b) Asym170.

The OSDAs were introduced directly inside the pores of these interrupted -SVR frame- 
works through the program $\mathrm{MCE}^{41}$ at the position reaveled by the difference Fourier maps. Soft restraints (bonds and angles) were added in order to maintain a suitable geometry for the OSDA but, as for the original structural study, $\stackrel{24}{n}$ no restraints on the distances between the OSDA and the inorganic framework were imposed. For sample Ref, after convergence of the refinement, Fourier difference maps revealed a positive electron density inside the channel close to a silicon atom which can be attributed to a fluoride ion or a water molecule. An oxygen atom was then introduced at this position and refined. The final Rietveld refinements gave good reliability factors; the Rietveld plots are displayed in Figure S1 and crystal as well as Rietveld refinement parameters are listed in Table 3 . The atomic and isotropic displacement parameters and the corresponding selected geometric parameters for Ref and Asym170 samples are listed, respectively, in Tables S1-S4. CCDC 2070516 and 2070517 contain the supplementary crystallographic data for this paper. The data can be obtained free of charge from The Cambridge Crystallographic Data Centre via https://www.ccdc.cam.ac.uk/structures/ 
Table 3: Crystal and Rietveld refinement data for samples Asym170 and Ref.

\begin{tabular}{|c|c|c|}
\hline Samples & Asym170 & $\operatorname{Ref}^{\mathrm{a}}$ \\
\hline Space group & \multicolumn{2}{|c|}{$C c(\# 9)$} \\
\hline$\lambda(\AA), \mathrm{Cu} \mathrm{K} \mathrm{K}_{\alpha 1}$ & \multicolumn{2}{|c|}{1.5406} \\
\hline Data collection temperature $\mathrm{T}(\mathrm{K})$ & \multicolumn{2}{|c|}{293} \\
\hline$a(\AA)$ & $20.4089(5)$ & $20.4560(10)$ \\
\hline$b(\AA)$ & $13.3862(1)$ & $13.3815(3)$ \\
\hline$c(\AA)$ & $20.1365(5)$ & $20.1138(12)$ \\
\hline$\beta\left(^{\circ}\right)$ & $102.702(2)$ & $102.266(4)$ \\
\hline$V\left(\AA^{3}\right)$ & $5366.61(7)$ & $5380.09(16)$ \\
\hline Number of data points, angular range $\left({ }^{\circ}\right)\left(\operatorname{step}\left({ }^{\circ} 2 \theta\right)\right)$ & \multicolumn{2}{|c|}{$8500,5.00-89.99(0.01)$} \\
\hline Number of contributing reflections & 2176 & 2182 \\
\hline Number of profile parameters & \multicolumn{2}{|c|}{5} \\
\hline Total number of refined parameters & 365 & 380 \\
\hline Total number of restraints (bonds, angles) & $374(140,234)$ & $395(149,246)$ \\
\hline Bond restraint weight factor & 75 & 50 \\
\hline Bond restraints: $\operatorname{mean}\left(w t \cdot \sum(\Delta / \sigma)^{2}\right)^{\mathrm{b}}$ & 21.65 & 11.64 \\
\hline Angle restraint weight factor & 40 & 30 \\
\hline Angle restraints: mean $\left(w t \cdot \sum(\Delta / \sigma)^{2}\right)^{\mathrm{c}}$ & 8.66 & 11.96 \\
\hline $\mathrm{d} R_{p}$ & 0.02572 & 0.03458 \\
\hline $\mathrm{d} w R_{p}$ & 0.03291 & 0.04381 \\
\hline${ }^{\mathrm{d}} R_{B}$ & 0.02577 & 0.03564 \\
\hline d $w R_{B}$ & 0.03080 & 0.04525 \\
\hline $\mathrm{d} w R_{\text {exp }}$ & 0.02501 & 0.02839 \\
\hline d $R_{F}$ & 0.03652 & 0.03465 \\
\hline${ }^{\mathrm{d}} R_{F^{2}}$ & 0.04235 & 0.03884 \\
\hline d $\mathrm{GOF}$ & 1.559 & 1.752 \\
\hline Largest differences peak and hole $\left(\bar{e} / \AA^{3}\right)$ & $0.290 ;-0.306$ & $0.269 ;-0.284$ \\
\hline \multicolumn{3}{|c|}{$\begin{array}{l}{ }^{\mathrm{a}} \text { The refined chemical formula per unit cell is }\left|\left(\mathrm{OSDA}^{2+}\right)_{4} ;\left(\mathrm{F}, \mathrm{H}_{2} \mathrm{O}\right)_{\mathrm{x}}\right|\left[\mathrm{Si}_{92} \square_{4} \mathrm{O}_{176}(\mathrm{OH})_{8}\left(\mathrm{O}^{-}\right)_{8}\right] \text { with } \\
\text { OSDA }=\mathrm{TM}\left[\mathrm{C}_{6}\right]\left(\mathrm{NC}_{4}\right) \text { and }\left(\mathrm{C}_{4} \mathrm{~N}\right)\left[\mathrm{C}_{6}\right]\left(\mathrm{NC}_{4}\right) \text { and } \mathrm{x}=0 \text { and } 1.56(4) \text { for Asym170 and Ref, respec- } \\
\text { tively. } \\
{ }^{\mathrm{b}} \sigma=0.04 \AA \text { for } \mathrm{Si}-\mathrm{O} \text { or } 0.03 \AA \text { for the organic bond distances. } \\
{ }^{\mathrm{c}} \sigma=4^{\circ} \text { for the } \mathrm{O}-\mathrm{Si}-\mathrm{O} \text { or } 3^{\circ} \text { for organic tetrahedral angles. }\end{array}$} \\
\hline
\end{tabular}

Computational details. In this section we aimed to compare the relative stability of two as-made SSZ-74 zeolites for which the symmetric OSDA $\left(\mathrm{C}_{4} \mathrm{~N}\right)\left[\mathrm{C}_{6}\right]\left(\mathrm{NC}_{4}\right)$ are differently oriented following the crystallographic works: (i) by Baerlocher et al. ${ }^{24}$ and (ii) by us in this work (sample Ref). For that purpose, we have applied the methodology devel- 
oped by Bushuev and Sastre in their original paper concerning the structural defects in SSZ-74 zeolite. ${ }^{25}$ First, we prepared the microscopic models of anhydrous as-made SSZ-74 zeolites refined in this work with the unit cell chemical composition expressed by the formula: $\left|\left(\mathrm{OSDA}^{2+}\right)_{4}\right|\left[\mathrm{Si}_{92} \square_{4} \mathrm{O}_{176}(\mathrm{OH})_{8}\left(\mathrm{O}^{-}\right)_{8}\right]$ (it is worth noting that no extra species such as fluoride or water molecules are introduced in both models). As suggested by this formula, creation of each defect produces two silanol groups ( $\equiv \mathrm{Si}-\mathrm{OH})$ and two siloxy groups $\left(\equiv \mathrm{Si}-\mathrm{O}^{-}\right)$thus leading to the presence of eight silanols per unit cell. Moreover, the silanols can be distributed in six different manners, according to the oxygen atoms hosting protons. In order to find the most stable(s) configuration(s) we prepared the microscopic models for all six possible distributions (designed as O3|O16; O3|O32; O3|O33; O16|O32; O16|O33; O32|O33, according to the cif file of the refined structure). The microscopic model of the anhydrous as-made SSZ-74 zeolite with the OSDA molecules positions determined by Baerlocher et al. 24 was taken from the Bushuev and Sastre publication. 25

After that, a force-field based geometry optimization using the non-polarizable BushuevSastre (BS) force field, able to reproduce with high accuracy the structure and the energetics of the pure silica zeolites was achieved. The detail of the interaction potentials and parameters are given in Table S5. The geometry optimizations of all considered systems were performed with the General Utility Lattice Program (GULP). ${ }^{42}$ The investigated structures were first transformed within the $P 1$ space group in order to avoid any symmetry constraint. Energy minimizations were carried under constant pressure allowing to fully relax both the atomic positions and the unit cell parameters. Consequently, the cell parameters on the geometry-optimized structures slightly varied in comparison with the Rietveld refined experimental structure. The evaluation of the electrostatic energy was achieved through the Ewald summation. The pseudo Newton-Raphson minimizing algorithm with the BFGS Hessian matrix updating scheme was applied. We systematically verified that a minimum on the hypersurface of potential energy has been reached through the final phonon calculation and subsequently checking the absence of soft vibrational modes. 


\section{Results and discussion}

Synthesis. The PXRD patterns of the samples prepared in fluoride-free conditions, listed in Table 1 and plotted in Figure 4, are compared to the one obtained according to Zones et al. protocol ${ }^{22}$ (sample Ref). It appears that well crystallized all-silica SSZ-74 zeolite has been synthesized by the fluoride-free routes (Asym160 and Asym170) using the new asymmetric OSDA $\left(\mathrm{TM}\left[\mathrm{C}_{6}\right]\left(\mathrm{NC}_{4}\right)\right)$ since the PXRD patterns are very close to the one of Ref sample. However, from the PXRD patterns of samples Sym160 and Sym170 are different. For Sym160 an unknown impurity appears on the PXRD pattern at about $7.5^{\circ} 2 \theta$ that is not present in Ref, Asym170 and Asym160 samples. As for Sym170, the product is not SSZ-74 but rather a zeolite of topology MFI. Anyhow, it is interesting to see that the symmetry of the organic molecule can influence the synthesis and direct it towards a purer and well crystallized sample in a fluoride-free procedure. Our results tend to prove that the synthesis of SSZ-74 is favored in presence of the asymmetric template when realized in fluoride-free media.

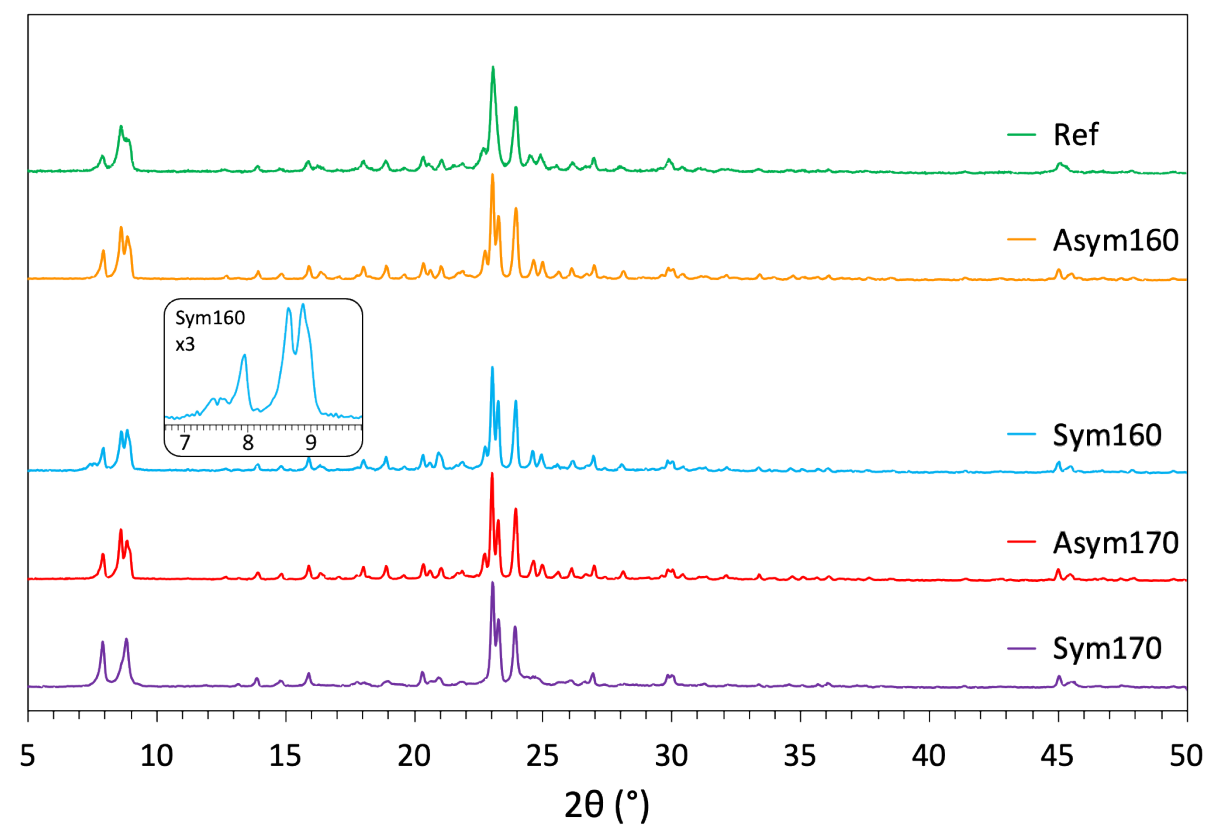

Figure 4: PXRD patterns of the SSZ-74 samples prepared in fluoride (Ref) and fluoride-free media (Asym160, Sym160, Asym170 and Sym170). 
Two of the best samples of -SVR-topology zeolite (Ref and Asym170 samples) have been further characterized. The samples are constituted of bundles resulting from the intergrowth of crystals (Figure S2). Ref sample has regular width crystals of about $90 \mathrm{~nm}$, which are finer than Asym170 which are from $300 \mathrm{~nm}$ to $7 \mu \mathrm{m}$ wide.

Thermogravimetric analyses. TGA of Ref and Asym170 samples are plotted in Figures S3 and S4. A negligible loss at temperatures under $200^{\circ} \mathrm{C}$ is visible. It is due to residual physisorbed water, coming from the external surface of the crystallites, where hydroxyl groups are present. The template decomposition, occurred under $450^{\circ} \mathrm{C}$, with a weight loss corresponding to four molecules per unit cell in every sample. The further weight loss can be attributed to a deshydroxylation.

High-temperature PXRD. The stability of SSZ-74 at high temperature is a key point for its potential large scale utilization. Even if calcination protocols have been proposed in many patents and publications, the structure that contains ordered vacancies may suffer under heating. For SSZ-74, there are strong interactions between the ordered silanol defects and the ammonium groups of the OSDA creating electrostatic interactions that stabilize the asmade product. A condensation of silanol groups looks impossible because of the localization of the vacancies within the $3 \mathrm{D}$ zeolitic framework ${ }^{24}$ unlike the possible polycondensation of well-ordered lamellar systems into zeolites after calcination. $\stackrel{43144}{\square}$

Ref sample was analysed by thermo-diffraction under air (Figure S6) and under inert atmosphere (Figure S7). The first change in the patterns occurred respectively from $300^{\circ} \mathrm{C}$ and $350{ }^{\circ} \mathrm{C}$ up to $400{ }^{\circ} \mathrm{C}$ and $450^{\circ} \mathrm{C}$ under air and helium. A significant increase in the relative intensities of reflections at low angles on PXRD patterns is the result of the release of porosity after the departure of organic molecules by calcination. Then, at higher temperatures, there is a significant loss of crystallinity which results in a broadening of the diffraction lines and a partial amorphization (see Figure S8), until a complete amorphiza- 
tion of the phase. The observed difference of temperature for the organic loss between the TGA and the HT PXRD performed under air experiments is explained by distinct temperature rises. Despite this instability observed after calcination, several studies show that SSZ-74 is active in several catalytic reactions $\frac{726 / 45 / 58}{58}$ and can be used for adsorption and gas separation. They tend to prove that there is still an accessible porosity after calcination. Nitrogen adsorption-desorption experiment confirmed that there is a remaining porosity, even after the observed loss of crystallinity for calcined Ref sample at $550{ }^{\circ} \mathrm{C}$ under air. The isotherms are mainly of type I characteristic of microporous solids (Figure S9). The values of the BET surface and the microporous volume are respectively $283.2 \mathrm{~m}^{2} \mathrm{~g}^{-1}$ and $0.11 \mathrm{~cm}^{3} \mathrm{~g}^{-1}$.

\section{Solid-state NMR}

${ }^{19}$ F MAS NMR. The ${ }^{19}$ F MAS NMR spectrum of Ref sample (Figure S11) is close to the one published in 2008 by Brunklaus et al., ${ }^{26}$ showing signals of different intensities between -60 and $-130 \mathrm{ppm}$. Except the sharp resonance at $-123.4 \mathrm{ppm}$ assigned to $\mathrm{SiF}_{6}^{2-}, \underline{5960}$ they can be attributed to fluoride hosted in $\left[4^{1} 5^{2} 6^{2}\right]\left(t\right.$-mel) or $\left[5^{8}\right](t$-pen) cages. The chemical shifts may indicate that they are linked to pentacoordinated silicon atoms, creating a distorted triangular bipyramid of formula $\mathrm{SiO}_{4 / 2} \mathrm{~F}^{-}$, the ${ }^{29} \mathrm{Si}$ MAS NMR spectra (see below) proves their existence but in a very small amount. According to the same authors, with a maximum of two disordered fluoride anions per unit cell and a possible dynamic exchanges between adjacent silicon sites and the existence of other vacancies, find the localization of fluoride ions by Rietveld refinement very difficult, or even impossible.

${ }^{29}$ Si MAS NMR. The ${ }^{29} \mathrm{Si}$ MAS NMR spectra of Ref and Asym170 samples (Figure 5 a

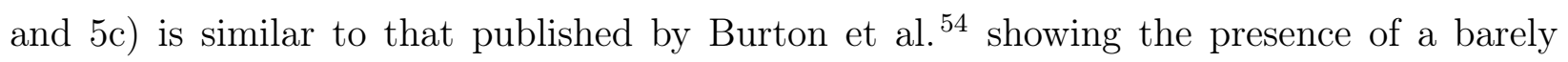
detectable amount of pentacoordinated silicon atoms $\left(\mathrm{SiO}_{4 / 2} \mathrm{~F}^{-}\right)$for Ref sample. The resolution of the ${ }^{29}$ Si MAS NMR spectra for Ref and Asym170 samples allowed us to deconvoluate separately the $\mathrm{Q}^{3}(\approx-94 \leftrightarrow-106 \mathrm{ppm})$ and $\mathrm{Q}^{4}(\approx-104 \leftrightarrow-130 \mathrm{ppm}) \mathrm{Q}$ sites 
(Figure 5b and 5d). In the original crystallographic study, ${ }^{24}$ the resolution of the ${ }^{29} \mathrm{Si}$ MAS NMR spectrum was lower with a higher noise/signal ratio and the $\mathrm{Q}^{3}$ sites were extracted with three components in the decomposition of the spectrum. It is worth mentioning that, for Ref and Asym170 samples and unlike the $\mathrm{Q}^{4}$ species, the silanol or siloxy groups generated by the silicon vacancies are well distinguished on the ${ }^{29}$ Si MAS NMR spectra. Here, the observed $\mathrm{Q}^{3}: \mathrm{Q}^{4}$ ratios are, respectively, 18:82 and 15:85 for Ref and Asym170, the simulation suggests relative intensities of 1:1:1:1 for the $\mathrm{Q}^{3}$ species. Taking into account the typical errors of about $5 \%$ for the decomposition of such spectra, these experimental proportions are in accordance with the -SVR framework ${ }^{24}$ since one silicon lacuna over 24 silicon $\mathrm{T}$ sites generates a $\mathrm{Q}^{3}: \mathrm{Q}^{4}$ ratio of 17.4:82.6. Unfortunately, from the ${ }^{1} \mathrm{H}-29 \mathrm{Si}$ CP-MAS NMR spectra (Figure 5a and 5), it is not possible to discern silanols from siloxy groups since ${ }^{1} \mathrm{H}-{ }^{29} \mathrm{Si}$ cross-polarization seems to affect all sites of concern reflecting a spatial proximity of the silanol and siloxy groups and also of some hydrogen atoms of the OSDAs as shown by the following crystallographic study. Bushuev and Sastre also established from atomistic simulations on as-synthesized SSZ-74 the presence of some water molecules near silanol nests but on the basis of the former structural study with the OSDA localized inside the channels down [001]. 25

Rietveld refinement. For Ref and Asym170 samples, the asymmetric units contains 23 T sites 48 framework oxygen atoms and one OSDA (Tables S1 and S2). Compared to the original structural analysis of SSZ-74,, 24 the main novelty resulting from the present Rietveld analyses lies in the unexpected position of the OSDAs inside the micropores, whereas the frameworks are identical to that already described by Baerlocher et al. ${ }^{24}$ The projections represented in Figures 6a and 6b show an orientation of the occluded OSDAs perpendicular relative to that observed previously as shown in Figure 2. The integrity of the OSDAs within the porosity was also proven by ${ }^{13} \mathrm{C}$ CPMAS NMR spectroscopy performed on Ref and Asym170 samples and ${ }^{13} \mathrm{C}$ liquid NMR after dissolution of the zeolites in HF (see 

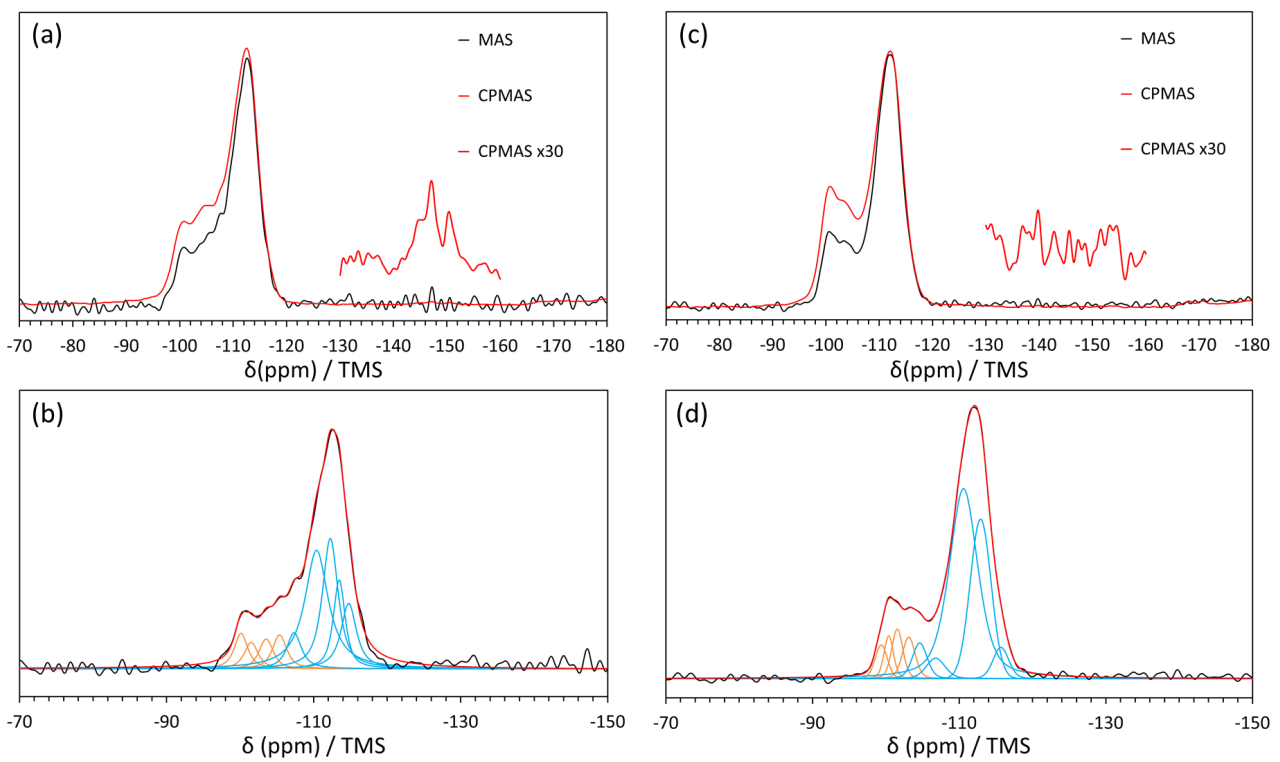

\begin{tabular}{|ccc|c|}
\hline Lines & $\delta(\mathrm{ppm})$ & Integrals $(\%)$ & Tot. \\
\hline $1\left(\mathrm{Q}^{3}\right)$ & -100.1 & 5 & \\
$2\left(\mathrm{Q}^{3}\right)$ & -101.5 & 4 & \\
$3\left(\mathrm{Q}^{3}\right)$ & -103.5 & 4 & \\
$4\left(\mathrm{Q}^{3}\right)$ & -105.4 & 5 & 18 \\
\hline $5\left(\mathrm{Q}^{4}\right)$ & -107.3 & 6 & \\
$6\left(\mathrm{Q}^{4}\right)$ & -110.4 & 32 & \\
$7\left(\mathrm{Q}^{4}\right)$ & -112.3 & 22 & \\
$8\left(\mathrm{Q}^{4}\right)$ & -113.5 & 11 & \\
$9\left(\mathrm{Q}^{4}\right)$ & -114.8 & 11 & 82 \\
\hline
\end{tabular}

\begin{tabular}{|ccc|c|}
\hline Lines & $\delta(\mathrm{ppm})$ & Integrals $(\%)$ & Tot. \\
\hline $1\left(\mathrm{Q}^{3}\right)$ & -99.4 & 3 & \\
$2\left(\mathrm{Q}^{3}\right)$ & -100.4 & 3 & \\
$3\left(\mathrm{Q}^{3}\right)$ & -101.6 & 5 & \\
$4\left(\mathrm{Q}^{3}\right)$ & -103.1 & 4 & 15 \\
\hline $5\left(\mathrm{Q}^{4}\right)$ & -104.6 & 4 & \\
$6\left(\mathrm{Q}^{4}\right)$ & -106.8 & 3 & \\
$7\left(\mathrm{Q}^{4}\right)$ & -110.6 & 50 & \\
$8\left(\mathrm{Q}^{4}\right)$ & -112.9 & 24 & \\
$9\left(\mathrm{Q}^{4}\right)$ & -115.7 & 4 & 85 \\
\hline
\end{tabular}

Figure 5: ${ }^{29} \mathrm{Si}$ MAS and ${ }^{1} \mathrm{H}^{-29} \mathrm{Si}$ CP-MAS NMR spectra of (a) Ref ( and (c) Asym170 samples. Decomposition of the ${ }^{29} \mathrm{Si}$ MAS NMR spectra of (b) Ref and (d) Asym170 samples, the corresponding percentages values of the different components are listed in the tables below. 
Figure S12). They are located inside the undulated channels along approximately the [110] direction and surprisingly not oriented in the 10-ring channels down the [001] direction. Due to this location, the OSDAs have more space and can adopt a more relaxed conformation, i.e. the central alkyl chain is more linear than that observed in the initial crystallographic study. $\stackrel{24}{24}$ From an energetic point of view, this occupation site in the -SVR framework, in the case of $\left(\left(\mathrm{C}_{4} \mathrm{~N}\right)\left[\mathrm{C}_{6}\right]\left(\mathrm{NC}_{4}\right)\right.$ OSDA, is supported by the molecular modeling study presented below.

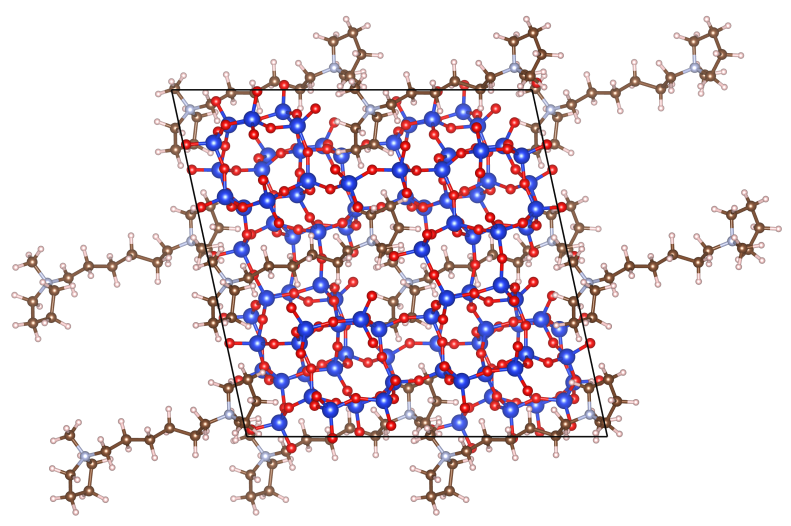

(a)

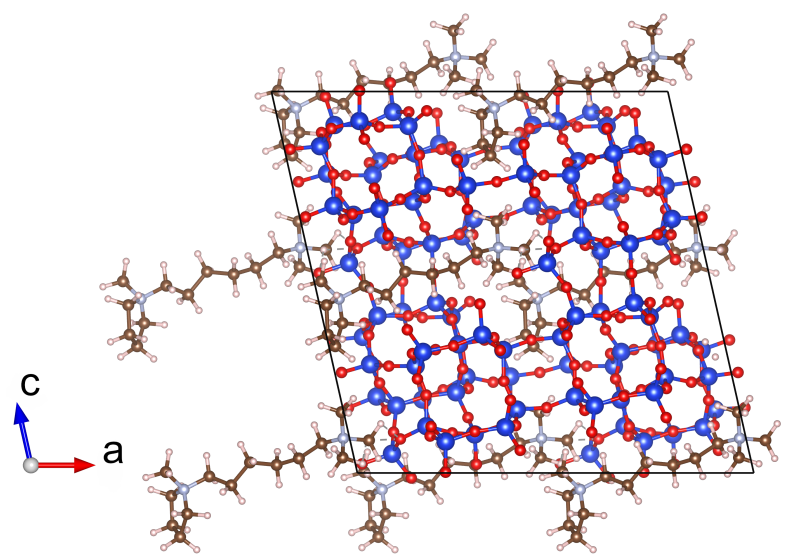

(b)

Figure 6: Projection along [010] of (a) Ref and (b) Asym170 structures showing the OSDAs $\left(\left(\mathrm{C}_{4} \mathrm{~N}\right)\left[\mathrm{C}_{6}\right]\left(\mathrm{NC}_{4}\right)\right.$ and $\left(\mathrm{TM}\left[\mathrm{C}_{6}\right]\left(\mathrm{NC}_{4}\right)\right)$ inside the undulated channels along approximately the [110] direction. The atoms are colored in blue for silicon, red for oxygen, brown for carbon, white for hydrogen and grey for nitrogen.

The hydrogen-bonding schemes for both structures are represented in Figure 7. For Ref (Figure 7a), in one side, three hydrogen atoms of a methyl group interact with the siloxy or silanol oxygen atom $\mathrm{O} 3$ and framework oxygen $\mathrm{O} 1$, the distances are $\mathrm{C} 9-\mathrm{H} 11 \cdots \mathrm{O} 3=$ $1.95(6) \AA, \mathrm{C} 9-\mathrm{H} 13 \cdots \mathrm{O} 3=1.92(4) \AA, \mathrm{C} 9-\mathrm{H} 12 \cdots \mathrm{O} 3=1.85(9) \AA$ and $\mathrm{C} 9-\mathrm{H} 11 \cdots \mathrm{O} 1=$ $1.96(4) \AA$ and one hydrogen of the pyrrolidine group with $\mathrm{C} 13-\mathrm{H} 22 \cdots \mathrm{O} 33=2.00(6) \AA$ in the opposite side. Concerning Ow1, when present (site occupancy factor $=0.43(4)$ ), it interacts with $\mathrm{H} 21(\mathrm{C} 12-\mathrm{H} 21 \cdots \mathrm{Ow} 1=1.90(12) \AA$. The distance between Ow1 and Si10 is 2.32(10) $\AA$, a distance too long to consider Si10 as a pentacoordinated silicon but we cannot 
totally exclude its presence according to Rietveld's analysis.

For Asym170 sample (Figure 7b), one methyl of the trimethylammonium group interacts with the framework similarly with $\mathrm{C} 7-\mathrm{H} 7 \mathrm{~A} \cdots \mathrm{O} 1=2.24(23) \AA, \mathrm{C} 7-\mathrm{H} 7 \mathrm{~B} \cdots \mathrm{O} 1=$ 1.75(12) $\AA, \mathrm{C} 7-\mathrm{H} 7 \mathrm{~B} \cdots \mathrm{O} 3=2.08(20) \AA$ and $\mathrm{C} 7-\mathrm{H} 7 \mathrm{C} \cdots \mathrm{O} 1=2.08(24) \AA$. The length of the OSDA TM $\left[\mathrm{C}_{6}\right]\left(\mathrm{NC}_{4}\right)$ being slightly shorter than that of $\left(\mathrm{C}_{4} \mathrm{~N}\right)\left[\mathrm{C}_{6}\right]\left(\mathrm{NC}_{4}\right)$, the strong interaction of the trimethylammonium group with the framework in Asym170 induces a distance from the pyrrolidinium group on the other side, $\mathrm{C} 12-\mathrm{H} 12 \mathrm{~A} \cdots \mathrm{O} 25=2.50(6) \AA$ is the shorter contact with the framework.

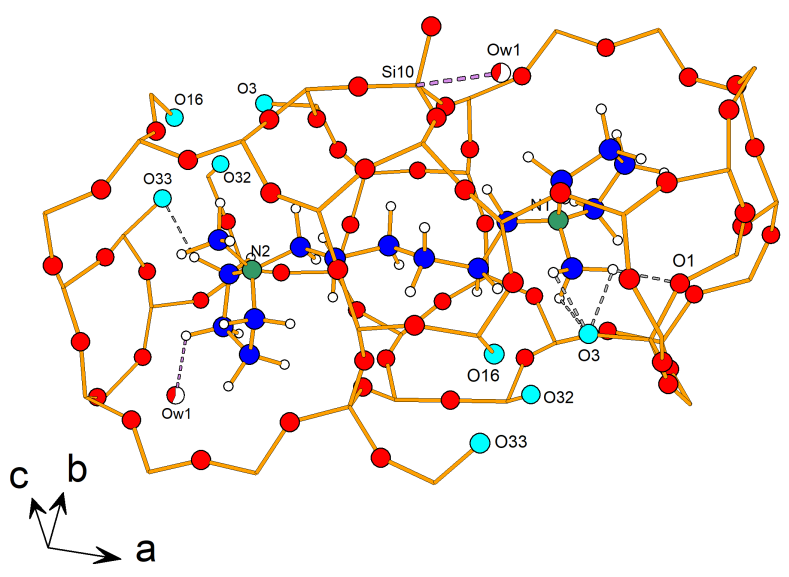

(a)

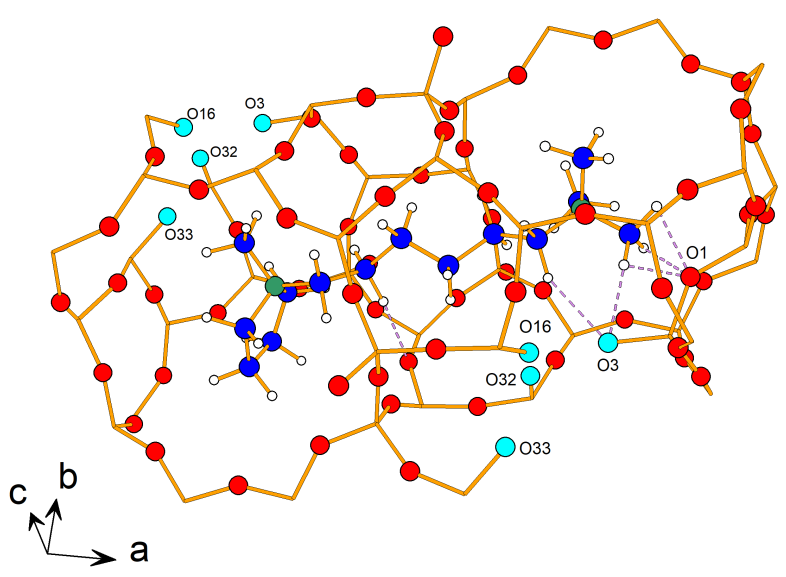

(b)

Figure 7: Hydrogen-bonding schemes of (a) Ref and (b) Asym170. The turquoise spheres are the silanol or siloxy groups, the red spheres the bridging framework oxygen atoms. For clarity, spheres have been omitted for Si atoms.

Relative stability of as-made SSZ-74 zeolites. The minimized energies of all investigated systems, presented in Table 4 evidence that the anhydrous as-made SSZ-74 structure with the OSDA oriented along the $c$-axis ${ }^{24}$ is the less stable one. The most stable structure corresponds to OSDA $\left(\mathrm{C}_{4} \mathrm{~N}\right)\left[\mathrm{C}_{6}\right]\left(\mathrm{NC}_{4}\right)$ oriented along the [110] direction with respectively oxygen O16 and O32 hosting protons. The shortest contacts between the OSDA and the framework involve hydrogen atoms with the siloxy and silanol groups, the shortest distance being of $2.42 \AA$. A detailed analysis of the optimized structures energy components high- 
lights systematically higher dihedral angle energy in the published former structure. An inspection of the dihedral angles of the OSDA molecules in both structures reveals a major difference between them: when the OSDA is oriented down [001] (Figure 2), the alkane chain connecting the side N-methyl-N-pyrrolidinium groups is mostly in syn conformation whereas, in this new crystallographic study, the chain conformation is all anti (Figure 8). The mean dihedral angles of the connecting alkane chains are of $83.7^{\circ}$ when parallel to the $c$-axis and of $170.1^{\circ}$ when parallel to the [110] direction. Consequently, the intramolecular distance between two N-methyl-N-pyrrolidinium groups is significantly shorter $(7.46(3) \AA)$ when it is oriented along [001 $]^{24}$ compared to the present SSZ-74 structure (Ref sample, 8.63(3) $\AA$ ). For the calculated model represented in Figure 8 , the four intramolecular $\mathrm{N}-\mathrm{N}$ distances per unit cell are equal, respectively, to $8.64,8.70,8.76$ and $8.75 \AA$, the average being $8.70 \AA$.

Moreover, the relative stability of the OSDA molecules in both conformations were estimated through Density Functional Theory (DFT) quantum mechanical calculations, using the Gaussian 09w suite with the B3LYP functional and 6-31+G(d,p) basis set. $\frac{61}{\text { The val- }}$ ues of energy showed higher relative stability of the all anti conformation by $32 \mathrm{~kJ} \mathrm{~mol}^{-1}$ $(0.33 \mathrm{eV})$ compared to the syn conformation. While this energy difference seems large compared to the thermal energy $\left(\sim 3.5 \mathrm{~kJ} \mathrm{~mol}^{-1}\right.$ at $150{ }^{\circ} \mathrm{C}$, the temperature of synthesis $)$, the difference in OSDA gas phase stability cannot be directly extended to its stability within the zeolite framework. 


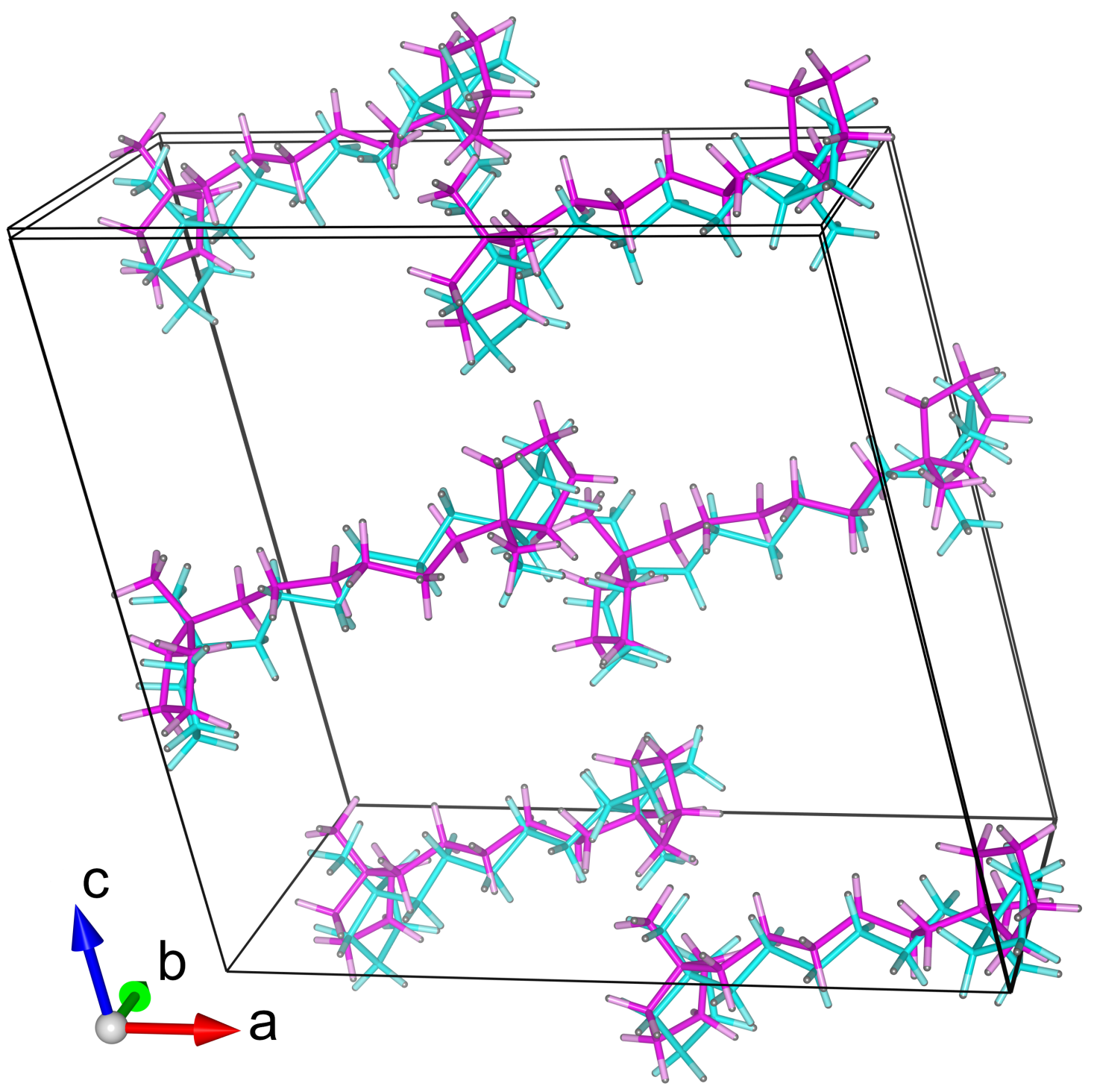

Figure 8: Overlay of the OSDAs $\left(\left(\mathrm{C}_{4} \mathrm{~N}\right)\left[\mathrm{C}_{6}\right]\left(\mathrm{NC}_{4}\right)\right)$ inside the unit cells of Ref sample (magenta sticks) after the final Rietveld refinement and inside the most stable computed model in space group $P 1$ (blue sticks) with $\mathrm{O} 16$ and $\mathrm{O} 32$ as the oxygen atoms of the two distinct silanol groups $\left(a=20.4039 \AA, b=13.3090 \AA, c=19.8394 \AA, \alpha=89.6123^{\circ}, \beta=\right.$ $102.4839^{\circ}$ and $\gamma=90.0765^{\circ}$ ). Due to removal of symmetry, the single OSDA in the $C c$ model is replaced by 4 independent molecules in the primitive $P 1$ cell 
Table 4: Relative stabilities of anhydrous as-made SSZ-74 zeolites with different arrangements of the silanol nests.

\begin{tabular}{cc}
\hline Structures & $\Delta \mathbf{E}(\mathrm{eV})$ \\
\hline${\text { OSDAs oriented along }[001]^{\mathrm{a}}}^{\mathrm{O}}$ & 1.74 \\
$\mathrm{O} 3 \mid \mathrm{O} 16^{\mathrm{b}}$ & 0.91 \\
$\mathrm{O} 3 \mid \mathrm{O} 32^{\mathrm{b}}$ & 0.25 \\
$\mathrm{O} 3 \mid \mathrm{O} 33^{\mathrm{b}}$ & 1.63 \\
$\mathrm{O} 16 \mid \mathrm{O} 32^{\mathrm{b}}$ & 0 \\
$\mathrm{O} 16 \mid \mathrm{O} 33^{\mathrm{b}}$ & 1.07 \\
$\mathrm{O} 32 \mid \mathrm{O} 33^{\mathrm{b}}$ & 0.16 \\
\hline
\end{tabular}

a References. 2425

b OSDA inside the channel oriented along [110].

\section{Conclusion}

It has been demonstrated that the synthesis of SSZ-74 zeolite can be performed in fluoridefree medium with two structurally related OSDAs but, preferably with the asymmetric 1methyl-1-[6-(trimethyl-azaniumyl)hexyl]pyrrolidinium rather than with the symmetric 1,6bis (N-methylpyrrolidinium)-hexane which is more efficient in fluoride media. Thermal stability of SSZ-74 structure has been studied by high-temperature PXRD. It shows that the changes in PXRD patterns appear from $300^{\circ} \mathrm{C}$ and $400^{\circ} \mathrm{C}$ under air and helium, respectively, followed by amorphization at higher temperature. Nevertheless, the material remains microporous until at least $550^{\circ} \mathrm{C}$. The structural study from powder X-rays diffraction of SSZ-74 zeolite revealed that the OSDAs are not located into the channels along [001] but into the undulated 10-ring channel following the [110] direction in an energetically more favorable conformation than in the former crystallographic study. This new insight on the structure of as-synthesized -SVR zeolite was also confirmed from computational considerations. 


\section{CRediT authorship contribution statement}

Carole Isaac: Investigation, Writing. Irena Deroche: Investigation, Writing. JeanLouis Paillaud: Conceptualization, Supervision, Investigation, Writing - Review \& Editing. Jean Daou: Supervision, Writing. Andrey Ryzhikov: Supervision, Writing. Laure Michelin: High temperature PXRD technical support. Séverinne Rigolet: solid-state NMR technical support. Ludovic Josien: SEM technical support. Habiba Nouali: $\mathrm{N}_{2}$ adsorption measurement technical support.

\section{Acknowledgement}

We thank the University of Upper Alsace (UHA) for the Doctoral grant to C. I. (Agreement No. 2018-61).

\section{Supporting Information}

Supporting information related to this article can be found free of charge at https://pubs. acs.org/doi/10.1021/acs.cgd.xxxxxxx

Atomic and isotropic displacement parameters for Ref and Asym170 samples, selected geometric parameters for Ref and Asym170 samples, BS force-field parameters (i.e., Tables S1-S5); SEM micrographs of -SVR samples, thermogravimetric analysis of samples Ref and Asym170, temperature profile of the HT-PXRD experiments, HT-PXRD experiments under helium on Ref sample, PXRD pattern after calcination under air of Ref sample, nitrogen physisorption isotherms of calcined Ref sample, T-plot of calcined Ref sample, ${ }^{19}$ F MAS NMR spectrum of Ref sample and ${ }^{13} \mathrm{C}$ CPMAS and liquid NMR spectra of Ref and Asym170 samples (i.e., Figures S1-S12). 


\section{References}

(1) Eroshenko, V.; Regis, R.-C.; Soulard, M.; Patarin, J. Energetics: A New Field of Applications for Hydrophobic Zeolites. J. Am. Chem. Soc. 2001, 123, 8129-8130.

(2) Soulard, M.; Patarin, J.; Eroshenko, V.; Regis, R.-C. In Recent Advances in the Science and Technology of Zeolites and Related Materials Part B; van Steen, E., Claeys, M., Callanan, L. H., Eds.; Stud. Surf. Sci. Catal.; Elsevier, 2004; Vol. 154; pp 1830-1837.

(3) Chen, N. Y. Hydrophobic Properties of Zeolites. J. Phys. Chem. 1976, 80, 60-64.

(4) Confalonieri, G.; Daou, T. J.; Nouali, H.; Arletti, R.; Ryzhikov, A. Energetic Performance of Pure Silica Zeolites under High-Pressure Intrusion of LiCl Aqueous Solutions: An Overview. Molecules 2020, 25, 21459.

(5) Cosseron, A.-F.; Daou, T. J.; Tzanis, L.; Nouali, H.; Deroche, I.; Coasne, B.; Tchamber, V. Adsorption of Volatile Organic Compounds in Pure Silica CHA, ${ }^{*}$ BEA, MFI and STT-Type Zeolites. Microporous Mesoporous Mater. 2013, 173, 147-154.

(6) Deroche, I.; Daou, T. J.; Picard, C.; Coasne, B. Reminiscent Capillarity in Subnanopores. Nat. Commun. 2019, 10, 1.

(7) Hunt, H. K.; Lew, C. M.; Sun, M.; Yan, Y.; Davis, M. E. Pure-Silica LTA, CHA, STT, ITW, and -SVR Thin Films and Powders for Low-K Applications. Microporous Mesoporous Mater. 2010, 130, 49-55.

(8) Mintova, S., Ed. Verified Synthesis of Zeolitic Materials, 3rd ed.; Synthesis Commission of the International Zeolite Association, 2016.

(9) Burton, A. Recent Trends in the Synthesis of High-Silica Zeolites. Catal. Rev. Sci. Eng. 2018, 60, 132-175. 
(10) Gómez-Hortigüela, L., Ed. Insights into the Chemistry of Organic Structure-Directing Agents in the Synthesis of Zeolitic Materials, Mingos, D. M. P. ed.; Struct. Bond. 175; Springer International Publishing, 2018.

(11) Bats, N.; Rouleau, L.; Paillaud, J.-L.; Caullet, P.; Mathieu, Y.; Lacombe, S. In Recent Advances in the Science and Technology of Zeolites and Related Materials Part A; van Steen, E., Claeys, I. M., Callanan, L. H., Eds.; Stud. Surf. Sci. Catal.; Elsevier, 2004; Vol. 154; pp 283-288.

(12) Caullet, P.; Paillaud, J.-L.; Mathieu, Y.; Bats, N. Synthesis of Zeolites in the Presence of Diquaternary Alkylammonium Ions as Structure-Directing Agents. Oil. Gas. Sci. Technol. 2007, 62, 819-825.

(13) Jackowski, A.; Zones, S. I.; Hwang, S.-J.; Burton, A. W. Diquaternary Ammonium Compounds in Zeolite Synthesis: Cyclic and Polycyclic N-Heterocycles Connected by Methylene Chains. J. Am. Chem. Soc. 2009, 131, 1092-1100.

(14) Kubů, M.; Millini, R.; Žilková, N. 10-Ring Zeolites: Synthesis, Characterization and Catalytic Applications. Catal. Today 2019, 324, 3-14.

(15) Isaac, C.; Paillaud, J.-L.; Daou, T. J.; Ryzhikov, A. Synthesis of BEC-Type Germanosilicates with Asymmetric Diquaternary Ammonium Salts. Microporous Mesoporous Mater. 2021, 312, (110804) 1-10.

(16) Guth, J.-L.; Kessler, H.; Higel, J. M.; Lamblin, J. M.; Patarin, J.; Seive, A.; Chezeau, J.M.; Wey, R. In Zeolite Synthesis; Occelli, M. L., Robson, H. E., Eds.; ACS Symposium Series; American Chemical Society, 1989; Vol. 398; Chapter 13, pp 176-195.

(17) Camblor, M.; Villaescusa, L.; Díaz-Cabañas, M. Synthesis of All-Silica and High-Silica Molecular Sieves in Fluoride Media. Top. Catal. 1999, 9, 59-76. 
(18) Burton, A. W.; Zones, S. I.; Elomari, S. The Chemistry of Phase Selectivity in the Synthesis of High-Silica Zeolites. Curr. Opin. Colloid Interface Sci. 2005, 10, 211-219.

(19) Zones, S. I.; Hwang, S.-J.; Elomari, S.; Ogino, I.; Davis, M. E.; Burton, A. W. The Fluoride-Based Route to All-Silica Molecular Sieves; a Strategy for Synthesis of New Materials Based Upon Close-Packing of Guest-Host Products. C. R. Chim. 2005, 8, $267-282$.

(20) Paillaud, J.-L.; Caullet, P.; Brendlé, J.; Simon-Masseron, A.; Patarin, J. In Functionalized Inorganic Fluorides: Synthesis, Characterization \& Properties of Nanostructured Solids; Traissaud, A., Ed.; John Wiley \& Sons, Ltd, 2010; Chapter 16, pp 489-518.

(21) Caullet, P.; Paillaud, J.-L.; Simon-Masseron, A.; Soulard, M.; Patarin, J. The Fluoride Route: a Strategy to Crystalline Porous Materials. C. R. Chimie 2005, 8, 245-266.

(22) Zones, S. I.; Burton, A. W. J.; Ong, K. Molecular Sieve SSZ-74 Composition of Matter and Synthesis Thereof. U.S. Patent 7,510,697 B2, March 31, 2009.

(23) Burton, A. W. J.; Zones, S. I. Synthesis of Molecular Sieve SSZ-74 Using a HydroxideMediated Gel. WO Patent 2010/099441 A3, September 2, 2010.

(24) Baerlocher, C.; Xie, D.; McCusker, L. B.; Hwang, S.-J.; Chan, I. Y.; Ong, K.; Burton, A. W.; Zones, S. I. Ordered Silicon Vacancies in the Framework Structure of the Zeolite Catalyst SSZ-74. Nat. Mater. 2008, 7, 631-635.

(25) Bushuev, Y. G.; Sastre, G. Atomistic Simulations of Structural Defects and Water Occluded in SSZ-74 Zeolite. J. Phys. Chem. C 2009, 113, 10877-10886.

(26) Brunklaus, G.; Koller, H.; Zones, S. I. Defect Models of As-Made High-Silica Zeolites: Clusters of Hydrogen-Bonds and Their Interaction with the Organic Structure-Directing Agents Determined from ${ }^{1} \mathrm{H}$ Double and Triple Quantum NMR Spectroscopy. Angew. Chem. Int. Ed. 2016, 55, 14459-14463. 
(27) Toby, B. H.; Khosrovani, N.; Dartt, C. B.; Davis, M. E.; Parise, J. B. Structure-directing Agents and Stacking Faults in the CON System: a Combined Crystallographic and Computer Simulation Study. Microporous Mesoporous Mater. 2000, 39, 77-89.

(28) McCusker, L. B.; Baerlocher, C. Using Electron Microscopy to Complement X-Ray Powder Diffraction Data to Solve Complex Crystal Structures. Chem. Commun. 2009, $1439-1451$.

(29) Xie, D.; Baerlocher, C.; McCusker, L. B. Using Phases Retrieved from Two-Dimensional Projections to Facilitate Structure Solution from X-Ray Powder Diffraction Data. J. Appl. Crystallogr. 2011, 44, 1023-1032.

(30) Li, Y.; Yu, J. New Stories of Zeolite Structures: Their Descriptions, Determinations, Predictions, and Evaluations. Chem. Rev. 2014, 114, 7268-7316.

(31) Rietveld, H. M. A Profile Refinement Method for Nuclear and Magnetic Structures. $J$. Appl. Crystallogr. 1969, 2, 65-71.

(32) Engelhardt, G.; Michel, D. High-Resolution Solid-State NMR of Silicates and Zeolites; John Wiley \& Sons, New York, 1987.

(33) Massiot, D.; Fayon, F.; Capron, M.; King, I.; Le Calvé, S.; Alonso, B.; Durand, J.O.; Bujoli, B.; Gan, Z.; Hoatson, G. Modelling One- and Two-Dimensional Solid-State NMR Spectra. Magn. Reson. in Chem. 2002, 40, 70-76.

(34) Rouquerol, J., Rouquerol, F., Kenneth, S., Eds. Adsorption by Powders and Porous Solids; Academic Press: London, 1999.

(35) Thommes, M.; Kaneko, K.; Neimark, A. V.; Olivier, J. P.; Rodriguez-Reinoso, F.; Rouquerol, J.; Sing, K. S. W. Physisorption of Gases, with Special Reference to the Evaluation of Surface Area and Pore Size Distribution (IUPAC Technical Report). Pure Appl. Chem. 2015, 87, 1051-1069. 
(36) Boultif, A.; Louër, D. Indexing of Powder Diffraction Patterns for Low-Symmetry Lattices by the Successive Dichotomy Method. J. Appl. Crystallogr. 1991, 24, 987-993.

(37) STOE \& Cie GmbH, WinX ${ }^{P O W}$, version 2.20, Darmstadt, Germany, 12 June 2006.

(38) Toby, B. H.; Von Dreele, R. B. GSAS-II: The Genesis of a Modern Open-Source all Purpose Crystallography Software Package. J. Appl. Crystallogr. 2013, 46, 544-549.

(39) Le Bail, A.; Duroy, H.; Fourquet, J. L. Ab-Initio Structure Determination of $\mathrm{LiSbWO}_{6}$ by X-ray Powder Diffraction. Mater. Res. 1988, 23, 447-452.

(40) McCusker, L. B.; Von Dreele, R. B.; Cox, D. E.; Louër, D.; Scardi, P. Rietveld Refinement Guidelines. J. Appl. Crystallogr. 1999, 32, 36-50.

(41) Rohlíček, J.; Hušák, M. MCE2005 - a New Version of a Program for Fast Interactive Visualization of Electron and Similar Density Maps Optimized for Small Molecules. J. Appl. Crystallogr. 2007, 40, 600-601.

(42) Gale, J. D. GULP: A Computer Program for the Symmetry-Adapted Simulation of Solids. J. Chem. Soc., Faraday Trans. 1997, 93, 629-637.

(43) Schreyeck, L.; Caullet, P.; Mougenel, J.-C.; Guth, J.-L.; Marler, B. PREFER: a New Layered (Alumino) Silicate Precursor of FER-type Zeolite. Microporous Mater. 1996, 6, 259-271.

(44) Eliášová, P.; Opanasenko, M.; Wheatley, P. S.; Shamzhy, M.; Mazur, M.; Nachtigall, P.; Roth, W. J.; Morris, R. E.; Čejka, J. The ADOR Mechanism for the Synthesis of New Zeolites. Chem. Soc. Rev. 2015, 44, 7177-7206.

(45) Kubů, M.; Zones, S. I.; Čejka, J. TUN, IMF and -SVR Zeolites; Synthesis, Properties and Acidity. Top. Catal. 2010, 53, 1330-1339.

(46) Kubů, M.; Opanasenko, M.; Shamzy, M. Modification of Textural and Acidic Properties of -SVR Zeolite by Desilication. Catal. Today 2014, 227, 26-32. 
(47) Zones, S. I.; Burton, A. W. J. Synthesis of Amines Using Molecular Sieve SSZ-74. U.S. Patent Application Publication 20070149819 A1, June 28, 2007.

(48) Zones, S. I.; Burton, A. W. Gas Separation Using Molecular Sieve SSZ-74. 2008; U.S. Patent Application Publication 20080115666 A1, May 22, 2008.

(49) Zones, S. I.; Burton, A. W. J. Partial Oxidation Using Molecular Sieve SSZ-74. 2008; U.S. Patent 7,432,402 B2, October 7, 2008.

(50) Zones, S. I.; Burton, A. W. J. Reduction of Oxides of Nitrogen in a Gas Stream Using Molecular Sieve SSZ-74. 2008; U.S. Patent 7,357,904 B2, April 15, 2008.

(51) Zones, S. I.; Burton, A. W. J. Acylation Using Molecular Sieve SSZ-74. U.S. Patent 7,473,807 B2, January 6, 2009.

(52) Zones, S.; Burton, A. W. J. Hydrocarbon Conversion Using Molecular Sieve SSZ-74. U.S. Patent Application Publication 20070144939 A1, June 28, 2007.

(53) Zones, S. I.; Burton, A. W. J. Treatment of Engine Exhaust Using Molecular Sieve SSZ-74. 2010; U.S. Patent 7,762,059 B2, July 27, 2010.

(54) Burton, A. W.; Zones, S. I.; Elomari, S.; Chan, I. Y.; Chen, C.-Y.; Hwang, S.-J.; Ong, K. In From Zeolites to Porous MOF Materials - The $40^{\text {th }}$ Anniversary of International Zeolite Conference; Xu, R., Gao, Z., Chen, J., Yan, W., Eds.; Stud. Surf. Sci. Catal.; 2007; Vol. 170 A; pp 690-697.

(55) Burton, A. W. J.; Zones, S. I. Oxygenate Conversion Using Molecular Sieve SSZ-74. U.S. Patent 7,485,766 B2, February 3, 2009.

(56) Hussain, A. I.; Palani, A.; Aitani, A. M.; Čejka, J.; Shamzhy, M.; Kubů, M.; AlKhattaf, S. S. Catalytic Cracking of Vacuum Gasoil over -SVR, ITH, and MFI Zeolites as FCC Catalyst Additives. Fuel Process. Technol. 2017, 161, 23-32. 
(57) Mehdipour Ghazi, M.; Mohammadi, M.; Modarres, H. Removal of Heavy Metal Particles by LTJ, ANA, SVR, BEC and MER Zeolites Particles: A Molecular Dynamics Simulation Study. J. P. S. T. 2015, 1, 99-111.

(58) Rahmati, M.; Modarress, H. Selectivity of New Siliceous Zeolites for Separation of Methane and Carbon Dioxide by Monte Carlo Simulation. Microporous Mesoporous Mater. 2013, 176, 168-177.

(59) Duke, C. V.; Miller, J. M.; Clark, J. H.; Kybett, A. P. A Comparison of the Adsorption of $\mathrm{KF}$ and $\mathrm{NH}_{4} \mathrm{~F}$ onto Silica Gel. Spectrochim. Acta A-M 1990, 46, 1381-1389.

(60) Klock, E.; Delmotte, L.; Soulard, M.; Guth, J.-L. F' a Multifunctional Tool for Microporous Solids b) ${ }^{19}$ F NMR of As-synthesized and Post-synthesis Treated Materials. Proceedings from the Ninth International Zeolite Conference. 1993; pp 611-618.

(61) Frisch, M. J. et al. Gaussian 09 Revision A.1. Gaussian Inc. Wallingford CT 2013. 


\section{For Table of Contents Use Only}

\section{All-Silica SSZ-74 Synthesized in Fluoride or Fluoride-Free Media: Investigation on the OSDA's Location Inside the Porosity}

Carole Isaac, Irena Deroche, Jean-Louis Paillaud, T. Jean Daou, Andrey Ryzhikov, Laure Michelin, Séverinne Rigolet, Ludovic Josien, and Habiba Nouali

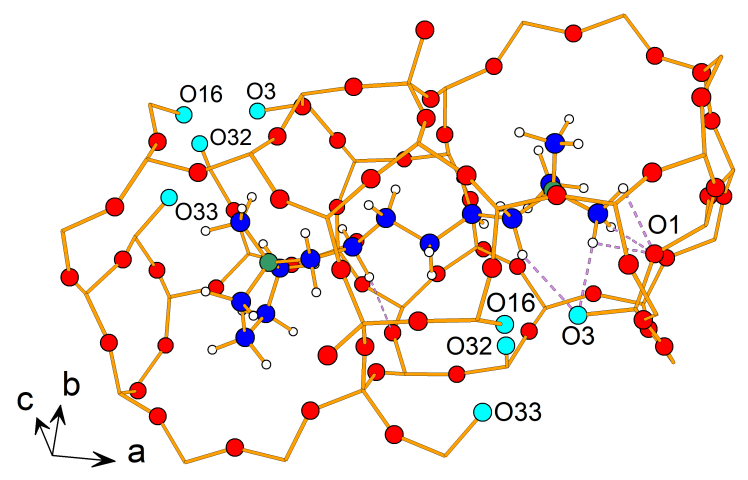

Synopsis : Structural study of two as-synthesized SSZ-74 zeolites by combined crystallographic and computational approaches revealed an unexpected orientation of OSDAs within pores. 